\title{
Evolutionary Theory and Political Behavior
}

\author{
Michael Bang Petersen \& Lene Aarøe
}

Michael Bang Petersen is Professor at the Department of Political Science \& Government, Aarhus University, Aarhus, Denmark.

E-mail:michael@ps.au.dk

Politics and Evolution Lab: www.ps.au.dk/ponelab

Lene Aarøe is Assistant Professor at the Department of Political Science \&

Governmen, Aarhus University, Aarhus, Denmark.

E-mail: leneaaroe@ps.au.dk

Politics and Evolution Lab: www.ps.au.dk/ponelab

Article prepared for

Emerging Trends in the Social and Behavioral Sciences

Edited by Robert A. Scott \& Stephen M. Kosslyn. Wiley Publishing.

\begin{abstract}
Political behavior is behavior aimed at regulating access to resources: Who is recognized to get what, when and how? Evidence across a number of disciplines show that humans over evolutionary history have evolved sophisticated abilities to engage in political behavior through status-seeking and coalition-formation in order to attract resources to themselves, their kin and their allies. As demonstrated by recent research this evolutionary history of politics continues to shape how modern individuals behave in modern mass politics and prompt people to derive their political attitudes from ancestrally relevant factors such as upper-body strength and short-term fluctuations in hunger. Important areas for research lies ahead in (a) understanding how evolution has given rise to individual variation in political behavior, (b) investigating the extent to which the evolved psychology of humans biases modern political behavior, and (c) strengthening the ties between this emerging application of evolutionary theory and more traditional research on political behavior.
\end{abstract}




\section{Introduction}

Political behavior is behavior aimed at regulating access to resources: Who is recognized to get what, when and how (Laswell, 1950)? If social behavior is about playing the game, political behavior is then about determining the rules of the game being played. For example, while many social animals can engage in cooperative exercises, only political animals can negotiate and change the rules regulating the surpluses flowing from these exercises. Humans are such political animals but other species are political too. In essence, any species with individually conflicting interests and cognitive capacities for what De Waal (1996) terms "a sense of social regularity" have politics. Conflicts of interest constitute the key driver of political behavior and the sense of social regularity (i.e., shared social expectations) constitutes the key target of political behavior. Political behavior is thus behavior seeking to enforce ones interests by pushing the shared sense of regularity into greater alignment with ones interest. Animals that are, presumably, political in this sense include a range of nonhuman species such as chimpanzees and dolphins (e.g., De Waal, 1982).

In this article, we focus on political behavior in humans. Yet, the observation that political behavior is zoologically widespread is important because it provides a prima facie case that political behavior in both human and non-human animals emerges from psychological mechanisms that are biologically instantiated and, as any other complex biological design, evolved by natural selection. This is critical important for the study of political behavior across all disciplines. If relevant psychological mechanisms are evolved biological adaptations, they are designed to carry out particular functions (Williams, 1966). Through the use of evolutionary theory, researchers can come to know the functions and structure of these psychology 
mechanisms and, ultimately, build precise testable hypotheses about political phenomena.

\section{Foundational Research}

The suite of psychological mechanisms underlying political behavior must encompass both mechanisms for evaluating current resource-access and mechanisms designed for engaging in activities that change access (Petersen \& Aarøe, 2012). Foundational research in evolutionary theory has explored the structure of both types of mechanisms.

\section{Adaptations for Political Judgment: Evaluating Resource Access}

In understanding the psychological mechanisms that underlie peoples intuitive evaluations of resource distributions, more general research on the evolution of social preferences have provided an important basis. Natural selection, of course, must have selected for a substantial degree of self-interest and, hence, a preference that more rather than less resources flow to the self. But, in addition, natural selection has selected for a number of pathways through which we are concerned with the welfare of others. These preferences in turn seem to influence the way that people evaluate resource allocations in the domain of politics.

Hamilton's (1964) demonstration of the fitness-advantages of helping kin (due to shared genes) provides the basis for understanding political phenomena such as kin nepotism. Even more important for the evolutionary study of political behavior was the demonstration by Trivers (1971) of the fitness-advantages of reciprocal cooperation. While Hamilton's work helped researchers understand preferences for 
providing resources to kin, Trivers' work helped researchers understand the conditions that regulate human preferences for providing resources to non-kin - a more pervasive category in most political settings. According to Trivers' model, people are motivated and capable of harvesting cooperative surpluses from interactions with non-kin but keep a keen eye on whether they are receiving less from the cooperative enterprise than they contribute (i.e., whether they are being "cheated"). Upon detection of cheating, cooperation is withdrawn. Research in experimental psychology has since provided strong demonstrations of the fine-tuned psychological mechanisms underlying both cooperative motivations and cheater-detection abilities (for reviews, see Cosmides \& Tooby, 2005). The general implication for the study of political behavior is that people intuitively favor resource distributions that match effort invested in collective enterprises and resource level and, in particular, that individuals oppose schemes that imply that they themselves receive less than they have contributed. In the study of politics, this has been used to explain the structure of institutions for collective action (Ostrom \& Walker, 2005), and attitudes towards social welfare recipients that are highly influenced by whether a recipient is putting in effort to alleviate his or her own need (Petersen, 2012).

Because cooperation requires stable exchange systems, cooperation evolved to operate within groups and, as consequence, a range of evolved, psychological mechanism for group-facilitation and -navigation exists (Tooby \& Cosmides, 2010). As demonstrated by foundational research in social psychology, these mechanisms prompt individuals to continuously track the group membership of other individuals (Kurzban et al., 2001) and to preferentially share resources with ingroup individuals (e.g., Yamagishi \& Mifune, 2008). Again, these mechanisms also influence political assessments of resource distributions such that individuals prefer resource access 
schemes that favor ingroup members at the expense of outgroup members. For example, studies of cross-national levels of ethnic heterogeneity and support for redistribution of income show that as heterogeneity increase people become more opposed to share their income (Alesina \& Glaeser, 2004).

\section{Adaptations for Political Behavior: Changing Resource Access}

Factors such as self-interest, kinship, reciprocity and group membership provide the foundations of our evolved psychology for evaluating political distributions of resources. In addition, we have an evolved psychology designed to bring these distributions into alignment with our preferences. Of key importance in this regard is the existence of hierarchies based on dominance and prestige (Cheng et al., 2010). As in many other social species, humans intuitively recognize differences in status and accept (within limits) that individuals of higher status have greater leverage in negotiations. As consequences, one of the key focal points of political conflict is status conflicts and, hence, conflicts about power to influence resource access.

For humans and a select number of other social animals, the key tool in such conflict is coalitions. One of the first explicitly evolutionary studies of political behavior was De Waal's (1982) study on politics among a troop of chimpanzees. This study documented how different male chimpanzees, through careful crafting of coalitions, climbed the hierarchical ladder in order to influence resource distributions and, in particular, access to females. Humans use similar tactics to regulate a wider range of resource distributions and receive significant political leverage through their allies. In fact, humans are probably unique in the extent to which strength in numbers (coalitional power) outweigh the role of physical strength of the individual (von Rueden et al., 2008). 
The sophisticated human abilities for navigating and forming coalitions and the resulting tight relationship between human coalitions and political power have had profound effects on the evolution of human political behavior. While coalitions have helped ambitious individuals gain power, coalitions have also enabled lower ranking individuals to revolt against overly ambitious (and overly self-serving) individuals. As argued by Boehm (2001), the constant possibility of the formation of coalitions "from below" have generated a zoologically unrivalled selection pressure for the evolution of an egalitarian orientation in humans and a resentment of exploitive leaders. Today, these orientations continue to shape political dynamics as civil war erupt and autocracies are revolted against when exploitation become to severe or number of high-ranking positions become to few (see, e.g., Axemoglu \& Robinson, 2000; Urdal, 2006).

For humans, not just individuals but also coalitions are organized in hierarchies (Sidanius \& Pratto, 2001). As consequence, political behavior is not just about achieving status for oneself but about achieving status - and, hence, recognized decision-making power - for the coalition that one is part of. A number of complex human political phenomena emerge from these coalitional competitions for status such as moral outrages to deteriorate opposing groups and epistemic bandwagoning whereby individuals adopt the epistemic attitudes of their group in order to signal group membership and loyalty (Tooby \& Cosmides, 2010). The most severe expression of these competitions is collective violence in the form of war. Both chimpanzees and humans engage in war or raids to secure tangible resources from other groups such as food, territory and mates. For human individuals and groups, resources gained from war also include status and, hence, political power. 


\section{Recent Research}

Recent advances in the study of the evolutionary origins of political behavior have focused on dissecting the structure of specific evolved mechanism for political behavior and narrowly defining the input they seek out and the output they deliver. Furthermore, a key concern of these recent advances has been whether it makes a difference for modern political behavior that it rests on evolved, biological underpinnings. In this way, scholars are increasingly moving from providing evolutionary explanations of well-known political phenomenon (e.g., war) to deriving novel predictions from the evolutionary perspective.

\section{The Ancestral Logic of Modern Politics}

An increasing set of studies have focused on the fact that biological evolution is a slow process and, hence, that the structure of biologically evolved psychological mechanisms is determined by past rather current environments (Tooby \& Cosmides, 1990). For the study of politics, this is important as there is a range of differences between the environments of ancestral and modern politics. Ancestrally, politics was played out between and within small groups of foragers of perhaps 25-200 individuals with Stone Age technology (Kelly, 1995), while today politics is played out between and within large-scale, highly technologically advanced societies with several millions inhabitants. As consequence, one way to identify the importance of biological evolution is to model ancestral environments and investigate whether factors that were adaptively important in these environments continue to shape political behavior even if these factors are rationally irrelevant today. 
Using this logic, upper-body strength is one factor that has been identified as politically important and it has been demonstrated that for males upper-body strength - a factor that ancestrally would have increased the likelihood of prevailing in conflict - correlates positively with modern support for war (Sell et al., 2009;) and self-serving policies (Petersen et al., 2013). While many modern political outcomes are determined through the electoral dynamics of representative democracy, individuals still reason as if outcomes were determined in direct face-to-face competition in which physical strength would partially determine who would prevail.

Another illustrative, ancestrally relevant factor that continues to shape modern political cognition is hunger. Our foraging ancestors regularly experienced periods of hunger. For humans, a key evolved strategy to buffer against fluctuations in calorie access was to motivate others to willful share their food. By implication, the human mind should contain psychological mechanisms designed to increase appeals to social sharing system when hungry and research has shown that these mechanisms extend their impact even to novel sharing systems such as the modern welfare states. In essence, short-term increases in hunger make people more supportive of social welfare (Aarøe \& Petersen, 2013; Petersen et al., 2014). While political scientists often have emphasized the role of economic resources that change only slowly, this research in contrast shows that our welfare attitudes change within an hour depending on short-term fluctuations in caloric resources.

A third recent illustration comes from research on disease-avoidance motivations and xenophobia. Ancestrally, modern "racial" differences did not exist and differences in skin complexion would rather be the result of infectious diseases (giving rise to symptoms such as rashes). Hence, the mind should be geared to automatically tag people who look different as potentially disease hosts (rather than 
carriers of different levels of harmless melanin) and avoid them (Kurzban \& Leary, 2001). In line with this, research has consistently and through a number of different study designs shown that people who are more oriented towards avoiding diseases are also more xenophobic (e.g., Faulkner et al., 2004). While political scientists have emphasized economic and cultural competition as an underlying cause of xenophobia, this research suggest that when foreigners are described as "vermin" and a "pest" it literally express a concern about pathogenic infection rather than economic or cultural concerns.

The underlying logic of these sets of studies is that researchers can predict the importance of seemingly irrelevant factors by considering the evolutionary history of politics. Human political psychology continues to bear the marks of the particular features of ancestral political environments. In this way, these studies have added significantly to the foundational research on evolution ad politics and clarified how evolution has shaped political behavior and why an evolutionary stance is important.

\section{Individual Political Differences}

The foundational research focused on human political universals such as dominance hierarchies and coalition formation. However, inspired by the fields of personality resarch and behavior genetics, recent research has demonstrated that political judgments and actions vary substantially from individual to individual. In particular, Haidt (2012) has provided strong evidence that show how liberals and conservatives utilize different evolved moral intuitions when thinking about politics and other research has shown that differences in political attitudes correlate with more basic physiological differences (Hibbing et al., 2013). Furthermore, a range of recent studies how consistently and cross-culturally documented that political ideology is 
between 40 and 60 percent heritable (Hatemi et al., 2014). A number of other traits related to both political judgments and behavior such as political participation have similarly been shown to be genetically heritable (e.g., Fowler et al., 2008). These recent findings indicate that there is no universally "best" political strategy. Rather, the fact that natural selection has left politically relevant genetic variation suggests that different political strategies, on average, have had equal fitness value over time.

\section{Key Issues for Future Research}

The evolutionary study of political behavior is a novel field and, hence, most discoveries have yet to be made and key obstacles has yet to be passed. The key issues for future research on the issue of evolutionary theory and political behavior can be divided into three parts: (1) investigating the precise relationships between the existence of universal, evolved psychological mechanisms for political behavior and the large levels of individual differences in manifest political behavior; (2) understanding the consequences of the differences between ancestral and modern political environments; and (3) increasing the acceptance of evolutionary approaches to politics within general social science. In this final section, we discuss each of these parts.

\section{Evolution and Political Individual Differences}

As described above, recent research has uncovered the existence of stable, partly genetic individual differences in political judgments and behavior. Evolutionary theory has most often been utilized to explain universals and, in this perspective, the existence of these individual differences could be viewed as puzzling. At the same 
time, it is important to acknowledge that evolutionary theorists for the last 30 years have been dissecting the many distinct pathways that can lead to adaptive existence of individual differences in general (e.g., Buss, 2009; Tooby \& Cosmides, 1990). Important research lies ahead in utilizing these accumulated insights to understand the emergences of individual differences in the domain of politics.

Part of the challenge is to understand the evolution of genetically heritable political traits within populations. As argued above, the key insight is that different political traits, on average, must have had equal fitness value over time. Yet, multiple processes could balance the fitness values of different political strategies. Frequencydependent selection is one such factor. Frequency-dependent selection for political traits would emerge if the adaptiveness of one political trait (e.g., a hawkish strategy) depended on the frequency of another trait (e.g., dovish strategies) in the population. Under specific conditions, a consequence of frequency-dependent selection is the evolution of different morphs of the species (Heino et al., 1998) and some authors have speculated that we can perhaps view liberals and conservatives as different political morphs of humans (Hibbing et al., 2013). Another factor that could uphold variation in politically relevant genes is continuously fluctuating or "noisy" environments (McElreath \& Strimling, 2006; Tooby \& Cosmides, 1990). This latter account seems more compatible with the fact that political ideology is normally distributed in modern populations rather than bimodally distributed as would be the case if discrete political morphs existed (see Fiorina \& Abrams, 2008). Teasing apart these (and other) different evolutionary accounts of the emergence of heritable differences in political behavior is an important step in future studies. Hence, each of these different accounts carry with them different observable implications that should be mapped out in detail and tested. 
The other part of the challenge is to understand the role of the environment in the shaping of stable individual differences in political behavior. As demonstrated in recent studies on individual differences on personality (e.g., Lukaszewski \& Roney, 2011; White et al., 2012), suites of mechanisms exists for tailoring personal temperament and strategies to the exact circumstances facing the specific individual. In the domain of politics, the above-cited studies demonstrating the calibration of political attitudes to both contextual factors such as exposure to hunger and disease threats and individual-level factors such as physical strength are examples in point. Adaptive political behavior is "state-dependent" or "facultative" behavior (Tooby \& Cosmides, 1990), i.e., behavior that matches the internal and external contingencies of the political actor (see Petersen \& Aarøe, 2012: 808). We should expect our evolved psychological architecture to reflect this and contain mechanisms for calibrating behavior accordingly. Using evolutionary theory to map the structure of these calibrational mechanisms and identify the cues that they are geared to use during development and in the present is a key important challenge for future studies. Ultimately, it holds the promise of replacing mushy concepts such as "political socialization" and "political learning" with clearly defined psychological processes.

\section{Evolutionary Matches and Mismatches in Modern Politics}

The structure of adaptations is determined by past environments. This opens for a range of important questions about how well human political psychology is adapted to modern mass politics. In essence, these questions relate to how modern environments are different from ancestral environments and how this affects the operations of evolved political psychology. 
A first set of issues relate to the quality of policies that rest on evolved moral and political intuitions. In the context of evolutionary matches and mismatches, one question in this regard is whether parts of our evolved minds lead us to misapprehend certain features of modern environments (Hagen \& Hammestein, 2006). If, for example, racially different immigrants are mentally tagged as pathogen hosts (as a byproduct of a hypervigilant disease-avoidance psychology) and therefore avoided and not allowed entry, it entails opportunity costs in the form potentially missed gains in productivity and innovation for a country. Another question relates to whether our intuitions provide appropriate solutions. If we, for example, are motivated to reduce crime (an evolved goal), is the solutions promoted by a psychology designed for small-scale social groups those that will work best in large-scale modern contexts (Petersen et al., 2010)? Such questions are important to address for future empirical research: How widespread are misapprehension and ill-working intuitions? This certainly does not mean that evolved mechanisms for political behavior are always illworking in modern politics. For example, in their pursuit for votes, office and policy, professional politicians make incredible use of the coalition-forming and -navigating abilities that has been installed in us by evolution. In this case, there is a high degree of similarity between the context of modern politics and ancestral politics. Coalitions are at the center of both and, for politicians, these coalitions are to a large extent negotiated in the kind of face-to-face interactions that have been pervasive over evolutionary history.

A second set of issues relates to the informational differences between ancestral and modern contexts in the domain of politics. In ancestral small-scale societies, direct knowledge of and acquaintance with targets of political decisions was the norm. Today, people have only indirect and only extremely limited knowledge of 
almost all political cases. The consequences of this difference are only now beginning to be explored and constitute important avenues for future research (Petersen, 2009; Petersen \& Aarøe, 2013). One avenue relates to the deeper causes of political disengagement. An evolutionary perspective suggest that in terms of psychology, we are all political sophisticates (Schreiber, 2007). Issues of criminal justice, social welfare and immigration carry, for example, deep similarities to recurrent adaptive problems of norm-violation, help-giving and ingroup-outgroup relations. Yet, for many people, modern politics fail to trigger the appropriate evolved mechanisms; not because they are impaired but because the abstract, anonymous and technical nature of mass politics imply that relevant ecologically valid information does not reach the mechanisms (Petersen \& Aarøe, 2012). Another avenue relates to the fact that today the political information provided to us has been carefully selected by journalists and editors to fulfill specific news criteria and have often been strategically provided to these by political elites in order to further their specific interests. This opens for the important study of whether political and media elites increase their power if their messages target evolved intuitions by placing emphasis on evolutionarily recurrent factors and solutions. The a priori expectation would be that political messages that fit our evolved intuitions should be more persuasive (e.g., Arceneaux, 2012).

A final set of issues relate to the emergence of large-scale societies themselves. Stable large-scale societies that are dramatically different from the societies of the past have emerged from a complex interplay between an evolved psychology designed for small-scale sociality and complex institutional change. How have political institutions successfully incentivized certain sides of human nature and succeed in disincentivizing other sides at bay in order for this to happen? Which 
institutional features have been most important and which psychological traits have they targeted? These are key challenges for 21 st century social science to solve.

\section{Evolutionary Theory and The General Study of Political Behavior}

Biological approaches to the study of political behavior has found it's way into toptier mainstream journals in diverse disciplines such as biology, psychology and political science. Yet, for some researchers, it might seem overly complicated to appeal to long evolutionary processes when explaining modern political behavior. At a glance, Occam's razor - the principle of utilizing the simplest explanation possible seems to go against evolutionary explanations. Yet, while evolutionary explanations might seem complicated from the perspective of a single discipline, they can easily emerge as the simplest explanations by considering the totality of interdisciplinary evidence.

For example: Why are physically stronger males more politically selfinterested (cf. Petersen et al., 2013)? Is this the result of an adaptation that is designed to regulate assertiveness on the basis of strength or is it simply because strong kids "learn" in the schoolyard that they can get their way? While the latter explanation for some might seem as a simpler account, it fails to account for why other organisms react in the same way (after all, spiders, frogs, crickets, deer etc. don't spend much time in school yards); the existence of sophisticated mechanisms for detecting strength in others; the incredibly large sexual dimorphism in strength; that preverbal infants social intuitions about who will prevail in a conflict are guided by cues to strength etc. Evolutionary theory provides a single explanation accounting for all these observations across all these disciplines (see Sell et al., 2012). 
One key practical challenge for the spread of the application of evolutionary theory to the study of political behavior, then, is to help other researchers appreciate the role of interdisciplinary evidence in evaluating theories of political behavior. This does not mean that specific studies of evolutionary theories should not be concerned with providing the strongest possible evidence on their own and the provisioning of cross-cultural evidence is in particular important here as is the (Henrich et al., 2010). But it means that the role of evolutionary theory in the study of political behavior is part of a larger, more general reorientation about what science is.

The success of an interdisciplinary stance in the natural sciences suggest that this stance too will be worthwhile in the social sciences including in the study of political behavior (Wilson, 1999). To paraphrase the evolutionary biologist, George Williams (1966: 16): is it not reasonable to anticipate that our understanding of the human political mind would be aided greatly by knowing the purpose for which it was designed? If so, to get to know that purpose, there is no other tool available than evolutionary theory.

\section{References}

Aarøe, L., \& Petersen, M. B. (2013). Hunger Games Fluctuations in Blood Glucose Levels Influence Support for Social Welfare. Psychological science, 24(12), $2550-2556$.

Acemoglu, D., \& Robinson, J. A. (2000). Democratization or repression?. European Economic Review, 44(4), 683-693.

Alesina, A., \& Glaeser, E. L. (2004). Fighting poverty in the US and Europe: A world of difference. Oxford University Press. 
Arceneaux, K. (2012). Cognitive biases and the strength of political arguments. American Journal of Political Science, 56(2), 271-285.

Boehm, C. (2000). Conflict and the evolution of social control. Journal of Consciousness Studies, 7(1-2), 1-2.

Buss, D. M. (2009). How can evolutionary psychology successfully explain personality and individual differences?. Perspectives on Psychological Science, $4(4), 359-366$.

Cheng, J. T., Tracy, J. L., \& Henrich, J. (2010). Pride, personality, and the evolutionary foundations of human social status. Evolution and Human Behavior, 31(5), 334-347.

Cosmides, L., \& Tooby, J. (2005). Neurocognitive adaptations designed for social exchange. The handbook of evolutionary psychology, 584-627.

De Waal, F. (1982). Chimpanzee politics: Power and sex among apes. JHU Press.

De Waal, F. B. (1996). Good natured. Harvard University Press.'

Faulkner, J., Schaller, M., Park, J. H., \& Duncan, L. A. (2004). Evolved diseaseavoidance mechanisms and contemporary xenophobic attitudes. Group Processes \& Intergroup Relations, 7(4), 333-353.

Fiorina, M. P., \& Abrams, S. J. (2008). Political polarization in the American public. Annu. Rev. Polit. Sci., 11, 563-588.

Fowler, J. H., Baker, L. A., \& Dawes, C. T. (2008). Genetic variation in political participation. American Political Science Review, 102(02), 233-248.

Hagen, E. H., \& Hammerstein, P. (2006). Game theory and human evolution: A critique of some recent interpretations of experimental games. Theoretical population biology, 69(3), 339-348. 
Haidt, J. (2012). The righteous mind: Why good people are divided by politics and religion. Random House LLC.

Hamilton, W. D. (1964). The genetical evolution of social behaviour. I. Journal of theoretical biology, 7(1), 1-16.

Hatemi, P. K., Medland, S. E., Klemmensen, R., Oskarsson, S., Littvay, L., Dawes, C. T., ... \& Martin, N. G. (2014). Genetic Influences on Political Ideologies: Twin Analyses of 19 Measures of Political Ideologies from Five Democracies and Genome-Wide Findings from Three Populations. Behavior genetics, 1-13.

Heino, M., Metz, J. A., \& Kaitala, V. (1998). The enigma of frequency-dependent selection. Trends in Ecology \& Evolution, 13(9), 367-370.

Henrich, J., Heine, S. J., \& Norenzayan, A. (2010). The weirdest people in the world?. Behavioral and Brain Sciences, 33(2-3), 61-83.

Hibbing, J. R., Smith, K. B., \& Alford, J. R. (2013). Predisposed: Liberals, Conservatives, and the Biology of Political Differences. Routledge.

Kelly, R. L. (1995). The foraging spectrum: Diversity in hunter-gatherer lifeways (pp. 295-297). Washington, DC: Smithsonian Institution Press.

Kurzban, R., \& Leary, M. R. (2001). Evolutionary origins of stigmatization: the functions of social exclusion. Psychological bulletin, 127(2), 187.

Kurzban, R., Tooby, J., \& Cosmides, L. (2001). Can race be erased? Coalitional computation and social categorization. Proceedings of the National Academy of Sciences, 98(26), 15387-15392.

Lasswell, H. D. (1950). Politics: Who gets what, when, how. New York: P. Smith.

Lukaszewski, A. W., \& Roney, J. R. (2011). The origins of extraversion: Joint effects of facultative calibration and genetic polymorphism. Personality and Social Psychology Bulletin, 37(3), 409-421. 
McElreath, R., \& Strimling, P. (2006). How noisy information and individual asymmetries can make 'personality'an adaptation: a simple model. Animal Behaviour, 72(5), 1135-1139.

Ostrom, E., \& Walker, J. (Eds.). (2005). Trust and reciprocity: Interdisciplinary lessons for experimental research (Vol. 6). Russell Sage Foundation.

Petersen, Michael Bang. 2009. "Public Opinion and Evolved Heuristics: The Role of Category-Based Inference". Journal of Cognition and Culture, vol. 9 no. 3, pp. $367-389$

Petersen, Michael Bang. 2012. "Social Welfare as Small-Scale Help: Evolutionary Psychology and the Deservingness Heuristic”. American Journal of Political Science, vol. 56, no. 1: 1-16.

Petersen, Michael Bang \& Lene Aarøe. 2012. "Is the Political Animal a Political Ignorant? Applying Evolutionary Psychology to the Study of Political Attitudes.” Evolutionary Psychology, vol. 10, no. 5: pp. 802-817.

Petersen, Michael Bang \& Lene Aarøe. 2013. "Politics in the Mind's Eye: Imagination as a Link between Social and Political Cognition." American Political Science Review, vol. 107, no. 2: pp. 275-293.

Petersen, M., Sell, A., Tooby, J., and Cosmides, L. (2010) Evolutionary Psychology and Criminal Justice: A Recalibrational Theory of Punishment and Reconciliation, from Human Morality \& Sociality: Evolutionary \& Comparative Perspectives, Henrik Høgh-Olesen (Ed.), Palgrave MacMillan, New York, pp. 72-131.

Petersen, Michael Bang, Daniel Sznycer, Aaron Sell, Leda Cosmides \& John Tooby. 2013. “The Ancestral Logic of Politics: Upper Body Strength Regulates Men’s 
Assertion of Self-Interest over Economic Redistribution.” Psychological Science, vol. 24, no. 7: 1098-1103.

Petersen, Michael Bang, Lene Aarøe, Niels Holm Jensen \& Oliver Curry. 2014. "Social Welfare and the Psychology of Food-Sharing: Short-Term Hunger Increases Support for Social Welfare.” Forthcoming in Political Psychology, available online under Early View.

Sell, A., Hone, L. S., \& Pound, N. (2012). The importance of physical strength to human males. Human Nature, 23(1), 30-44.

Sell, A., Tooby, J., \& Cosmides, L. (2009). Formidability and the logic of human anger. Proceedings of the National Academy of Sciences, 106(35), 1507315078.

Sidanius, J., \& Pratto, F. (2001). Social dominance: An intergroup theory of social hierarchy and oppression. Cambridge University Press.

Tooby, J., \& Cosmides, L. (1990). On the universality of human nature and the uniqueness of the individual: The role of genetics and adaptation. Journal of personality, 58(1), 17-67.

Tooby, J., \& Cosmides, L. (1992). The psychological foundations of culture. The adapted mind: Evolutionary psychology and the generation of culture, 19-136.

Tooby, J., \& Cosmides, L. (2010). Groups in mind: The coalitional roots of war and morality. Human morality and sociality: Evolutionary and comparative perspectives, 91-234.

Trivers, R. L. (1971). The evolution of reciprocal altruism. Quarterly review of biology, 35-57.

Urdal, H. (2006). A clash of generations? Youth bulges and political violence. International Studies Quarterly, 50(3), 607-629. 
Von Rueden, C., Gurven, M., \& Kaplan, H. (2008). The multiple dimensions of male social status in an Amazonian society. Evolution and Human Behavior, 29(6), $402-415$.

White, A. E., Kenrick, D. T., Li, Y. J., Mortensen, C. R., Neuberg, S. L., \& Cohen, A. B. (2012). When nasty breeds nice: Threats of violence amplify agreeableness at national, individual, and situational levels. Journal of personality and social psychology, 103(4), 622.

Williams, G. C. (1966). Adaptation and natural selection: a critique of some current evolutionary thought. Princeton University Press.

Wilson, E. O. (1999). Consilience: The unity of knowledge. Vintage Books.

Yamagishi, T., \& Mifune, N. (2008). Does shared group membership promote altruism? Fear, greed, and reputation. Rationality and Society, 20(1), 5-30. 


\section{Bios}

Michael Bang Petersen is Professor at the Department of Political Science \& Government, Aarhus University in Denmark. He received his $\mathrm{PhD}$ in 2007. His primary research focuses on how human evolutionary history influences the way people reason about modern mass politics. Specific topics he has published on include attitudes about social welfare, immigration, redistribution, criminal justice and political parties. His work has appeared in journals such as Psychological Science, American Political Science Review, American Journal of Political Science and Journal of Politics. His academic affiliations include the Center for Evolutionary Psychology at University of California, Santa Barbara and the Interacting Minds Centre at Aarhus University. Together with Lene Aarøe, he co-directs The Politics and Evolution Lab.

Lene Aarøe is Assistant Professor at the Department of Political Science \& Government, Aarhus University in Denmark. She received her PhD in 2010. Her field of research is political psychology. A key motivation in her work is to investigate how the psychological imprints of ancestral living in hunter-gatherer groups shape political attitudes and communication effects in modern mass democracies. Specific topics she has published on include attitudes about social welfare, immigration, and political parties. Her work has appeared in journals such as Psychological Science, American Political Science Review, Journal of Politics and Political Communication. She is affiliated with the Interacting Minds Centre at Aarhus University and, together with Michael Bang Petersen, she co-directs The Politics and Evolution Lab. 